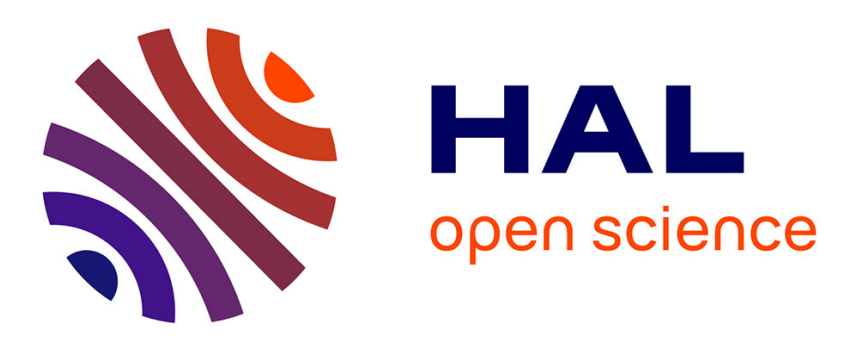

\title{
A Method for Determination of Porosity Change from Shrinkage Curves of Deformable Materials
}

J. Madiouli, D. Lecomte, T. Nganya, S. Chavez, J. Sghaier, H. Sammouda

\section{To cite this version:}

J. Madiouli, D. Lecomte, T. Nganya, S. Chavez, J. Sghaier, et al.. A Method for Determination of Porosity Change from Shrinkage Curves of Deformable Materials. Drying Technology, 2007, 25 (4), p.621-628. 10.1080/07373930701227185 . hal-01925866

\section{HAL Id: hal-01925866 https://hal.science/hal-01925866}

Submitted on 18 Nov 2018

HAL is a multi-disciplinary open access archive for the deposit and dissemination of scientific research documents, whether they are published or not. The documents may come from teaching and research institutions in France or abroad, or from public or private research centers.
L'archive ouverte pluridisciplinaire HAL, est destinée au dépôt et à la diffusion de documents scientifiques de niveau recherche, publiés ou non, émanant des établissements d'enseignement et de recherche français ou étrangers, des laboratoires publics ou privés. 


\title{
A Method for Determination of Porosity Change from Shrinkage Curves of Deformable Materials
}

\author{
J. Madiouli, ${ }^{1}$ D. Lecomte, ${ }^{2}$ T. Nganya, ${ }^{2}$ S. Chavez, ${ }^{2}$ J. Sghaier, ${ }^{1}$ \\ and H. Sammouda ${ }^{1}$ \\ ${ }^{1}$ LETTM, Faculté des sciences de Tunis, Tunis, Tunisie \\ ${ }^{2}$ Centre RAPSODEE, Ecole des Mines d'Albi-Carmaux, Albi, France
}

\begin{abstract}
Among the numerous models developed to predict the shrinkage of materials during drying, the model developed by Katekawa and Silva $^{[1]}$ gives a general relationship between shrinkage and porosity with a limited number of parameters such as initial density of the wet product, true density of the solid phase, and true density of the liquid phase. A graphical interpretation of this model is proposed to visualize the changes of porosity by comparing the experimental shrinkage curve with an ideal one. Four examples are given to illustrate the applicability of the model using different materials (carrot, banana, xerogel, and sludge), two types of the solvent (water, isopropanol), and two drying technologies (convective drying, freeze drying). Porosity calculations were found to be very consistent and complementary with porosity measurements.
\end{abstract}

Keywords Banana; Carrot; Drying; Modeling; Porosity; Shrinkage; Sludge; Xerogel

\section{INTRODUCTION}

During chemical, mechanical, or thermal treatments, deformable materials can undergo modifications of their volume depending, for instance, on the evaporation of a solvent or release of a chemical species such as $\mathrm{CO}_{2}$ in calcination or light hydrocarbons $\left(\mathrm{CH}_{4}, \mathrm{C}_{2} \mathrm{H}_{4}, \mathrm{C}_{2} \mathrm{H}_{6}, \ldots\right)$ in pyrolysis of plastics. This is the case of wood, ${ }^{[2]}$ xerogels, ${ }^{[3]}$ sludge, ${ }^{[4]}$ clays,${ }^{[5]}$ paper,,${ }^{[6]}$ and food products, ${ }^{[7-14]}$ among many others reported in the scientific literature.

Often, these modifications to the material structure have a consequence on the process performance or on the product quality. For instance, during drying of deformable capillary-porous media, the mass flux density may be constant (in the "constant drying rate period"), but the decrease of the external surface area results in a decreasing drying rate. This phenomenon was observed and measured experimentally by May and Perré ${ }^{[13]}$ for foodstuffs and

Correspondence: Didier Lecomte, Centre RAPSODEE (UMR 2392), Ecole des Mines d'Albi-Carmaux, Route de Teillet, Campus Jarlard 81013 Albi, France; E-mail: lecomte@enstimac.fr
Leonard $^{[15]}$ for sludge. Volume reduction in foodstuffs frequently contrasts the consumers' expectations. Other examples show, however, that shrinkage may be beneficial. For example, densification of crystallized hydroxyapatites used to trap heavy metals during calcination limits the risk of leaching undesirable heavy metals into soils. ${ }^{[16]}$

The objectives of the present study are to validate a general model based on mass balance equations, with a limited number of parameters, to predict the shrinkage of various materials. This model can also be used in comparison with experimental data to estimate porosity changes in the material structure. Examples will be provided for two drying technologies, two types of moisture, and four types of dramatically different materials.

\section{BACKGROUND TO SHRINKAGE}

In the case of drying, shrinkage is a consequence of the evaporation of a solvent contained in a solid matrix. If the volume reduction is strictly proportional to the mass loss, the shrinkage is regarded as the ideal one. On the other hand, if the volume reduction is smaller than the volume of evaporated water, the drying operation generates an increase in the material porosity. The structure of the dry product is strongly dependent on the nature of the material as well as on the drying conditions. ${ }^{[12]}$ The majority of available correlations are empirical ${ }^{[4,9,10,14,17-20]}$ and cannot be transposed to other products or other experimental conditions. Although the theory-based models can also be found in the literature, ${ }^{[21]}$ the multiplicity of graphic representations and physical properties (density, concentrations, shrinkage coefficient, collapse, porosity, volume change) make comparisons very difficult. The models developed on a microscopic scale introduce additional parameters such as capillary pressure or surface tension of solvents. ${ }^{[22]}$

The first models of ideal shrinkage were developed by Kilpatrick et al. ${ }^{[23]}$ and Suzuki et al. ${ }^{[2]}$ These models have been used by several authors with various forms and applications. The ideal shrinkage was observed for convective 
TABLE 1

Different expressions for the shrinkage parameter

\begin{tabular}{lcc}
\hline Parameter & Correlation & (Dimension) \\
\hline Collapse & $\frac{V-V_{0}}{V_{0}-V_{e}}$ & - \\
Specific volume & $\frac{V}{m_{S}}$ & $\mathrm{~m}^{3} \cdot \mathrm{kg}^{-1}(\mathrm{db})$ \\
Bulk shrinkage coefficient & $\frac{V}{V_{0}}$ & - \\
Shrinkage & $\frac{100\left(V_{0}-V\right)}{V_{0}}$ & $\%$ \\
\hline
\end{tabular}

drying of carrot. $^{[8,12]}$ Potato, ${ }^{[8,25]}$ apple, ${ }^{[7]}$ grapes, ${ }^{[26]}$ banana, ${ }^{[27]}$ and squid ${ }^{[28]}$ showed an almost ideal behavior. A recent bibliographical survey of food shrinkage models during drying was developed by Mayor and Sereno. ${ }^{[14]}$ In the works of Perez and Calvelo ${ }^{[29]}$ and Rahman et al., ${ }^{[1]}$ the porosity of dried products is explicitly used in theorybased models. The initial porosity may also be accounted for. ${ }^{[8,14]}$ In these types of models, the bulk shrinkage coefficient $\left(V / V_{0}\right)$ is often (but not solely) expressed as a function of the mass reduction $\left(X / X_{0}\right)$, with a number of parameters ranging between 3 and 5 .

The shrinkage of a product can be expressed in terms of the specific volume, the collapse, and the shrinkage ratio (Table 1). The use of a collapse parameter ${ }^{[30]}$ is useful to follow the progress of the shrinkage compared to the final volume. The specific volume is more suitable to compare the evolution of strictly identical samples because this parameter will give a first indication of the differences in porosity. The shrinkage ratio is a good indicator of the mass loss in percent during a process. In the next section, the shrinkage will be expressed as $V / V_{0}=f\left(X / X_{0}\right)$ where $X / X_{0}$ is the reduced moisture content of the sample. The corresponding diagram will be called the "shrinkage diagram."

Krokida and Maroulis ${ }^{[12]}$ confirmed that the influence of a drying method on the shrinkage of a food product is very important; convective drying and osmotic dehydration lead to small porosities and large shrinkage, whereas freeze drying leads to almost no shrinkage and a large porosity. For non-food products and especially clays, the shrinkage is ideal down to certain critical moisture content. For clays the critical water content is defined from the Bigot curve ${ }^{[5]}$ and corresponds to the end of the evaporation of the colloidal water. Free water between the colloids is then removed without volume change. ${ }^{[31]}$ For wood $^{[32]}$ and sludge, ${ }^{[4]}$ similar behaviors were observed.

The majority of developed models were validated by experiments. The classical methods used scales for the mass measurements and picnometers or metric measurements for the determination of the volume. New dimensional techniques were recently developed, like dynamic mechanical analysis (DMA), which combines metric and mass measurements on a small sample under controlled atmosphere. DMA can provide the volumetric shrinkage and the plasticity modulus as a function of time. ${ }^{[33]}$ Slowik et al. ${ }^{[34]}$ used an experimental setup based on the principle of light diffraction for the followup of the shrinkage of the concrete during the first stages of drying. The drying of municipal sewage sludge was monitored using X-ray tomography combined with image processing, which permits following the changes of the product surface (including cracks). This express technique (less than two minutes of processing) allowed precise and noninvasive measurements. ${ }^{[15]}$ Another noninvasive technique is the monitoring of concrete shrinkage in an environmental scanning electron microscope (ESEM). This technique, also used with image processing, ${ }^{[30]}$ allowed volumetric measurements (but no weight measurement) and local observations like cracks on materials containing liquids at relatively high pressures compared to conventional SEM. Lastly, an experimental setup developed by May and Perré ${ }^{[13]}$ used a laser beam at high speed to follow the evolution of the diameter and length of fruit samples during drying.

\section{MODEL FORMULATION AND TARGETED SOLUTIONS}

A wet material with an initial water content $X_{0}$, initial volume $V_{0}$, initial apparent density $\rho_{0}$, and initial porosity $\varepsilon_{0}$ is dried, dewatered, or kilned under controlled conditions. The material is composed of a solid matrix $\mathrm{S}$, with a true density $\rho_{S}$, a solvent $\mathrm{L}$ with a true density $\rho_{L}$, and air. At time $t$, the volume is $V$, the density is $\rho$, the moisture content is $X$, and the porosity is $\varepsilon$. The only assumptions of the shrinkage model are those of the additivity of volumes and mass conservation.

The solvent conservation equation leads to the following expression: $:^{[1,29]}$

$$
\frac{\rho V}{\rho_{0} V_{0}}=\frac{1+X}{1+X_{0}}
$$

The apparent density is the sum of the mass concentrations of the liquid and solid phases (the concentration of the gas phase is neglected).

$$
\begin{gathered}
\rho=\varepsilon_{L} \rho_{L}+\left(1-\varepsilon-\varepsilon_{L}\right) \rho_{S} \\
\rho_{0}=\varepsilon_{L 0} \rho_{L}+\left(1-\varepsilon_{0}-\varepsilon_{L 0}\right) \rho_{S}
\end{gathered}
$$

where the liquid fraction $\varepsilon_{L}$ (resp. $\varepsilon_{L 0}$ ) is related to the moisture content $X$ (resp. $X_{0}$ ) by the following equations:

$$
\begin{aligned}
\varepsilon_{L} & =\frac{\rho}{\rho_{L}} \frac{X}{1+X} \\
\varepsilon_{L 0} & =\frac{\rho_{0}}{\rho_{L}} \frac{X_{0}}{1+X_{0}}
\end{aligned}
$$

Introducing the parameter $\beta=\rho_{S} / \rho_{L}$, Eqs. (1) through (5) can be combined to yield:

$$
\frac{(1-\varepsilon)}{\left(1-\varepsilon_{0}\right)} \frac{V}{V_{0}}=A(\beta) \frac{X}{X_{0}}+B(\beta)
$$




$$
\begin{aligned}
& A(\beta)=\frac{X_{0} \beta}{1+\beta X_{0}} \\
& B(\beta)=\frac{1}{1+\beta X_{0}}
\end{aligned}
$$

This set of equations, first established by Katekawa and Silva, ${ }^{[1]}$ shows that the quantity $(1-\varepsilon) V /\left(1-\varepsilon_{0}\right) V_{0}$ varies linearly with the mass reduction $X / X_{0}$. The governing parameters of the shrinkage are the initial porosity $\varepsilon_{0}$ and the true densities of the solvent $\rho_{L}$ and solid $\rho_{S}$ phases.

The following basic cases can be examined.

\section{Case (a): Ideal Shrinkage without Initial Porosity; $\varepsilon=0$,} $\boldsymbol{\varepsilon}_{\mathbf{0}}=\mathbf{0}$

In this case, the ideal shrinkage curve $y$ is linear and can be written in the form:

$$
y=\frac{V}{V_{0}}=A(\beta) \frac{X}{X_{0}}+B(\beta)
$$

This expression was first established by Vacarezza ${ }^{[35]}$ and used for modeling the shrinkage of vegetables. The representation of the ideal shrinkage curve is shown in Fig. 1.

\section{Case (b) Ideal Shrinkage with Initial Porosity; $\varepsilon=\varepsilon_{0}$, $\boldsymbol{\varepsilon}_{\mathbf{0}} \neq \mathbf{0}$}

The case of ideal shrinkage with initial porosity is typical for non-saturated porous materials such as wood. Internal porosity remains constant and equal to the initial porosity during the shrinkage process. Equation (6) may be simplified to yield the same expression as Eq. (9). Thus, the internal porosity does not affect the shrinkage curve, which remains the same as in case (a). This result contra-

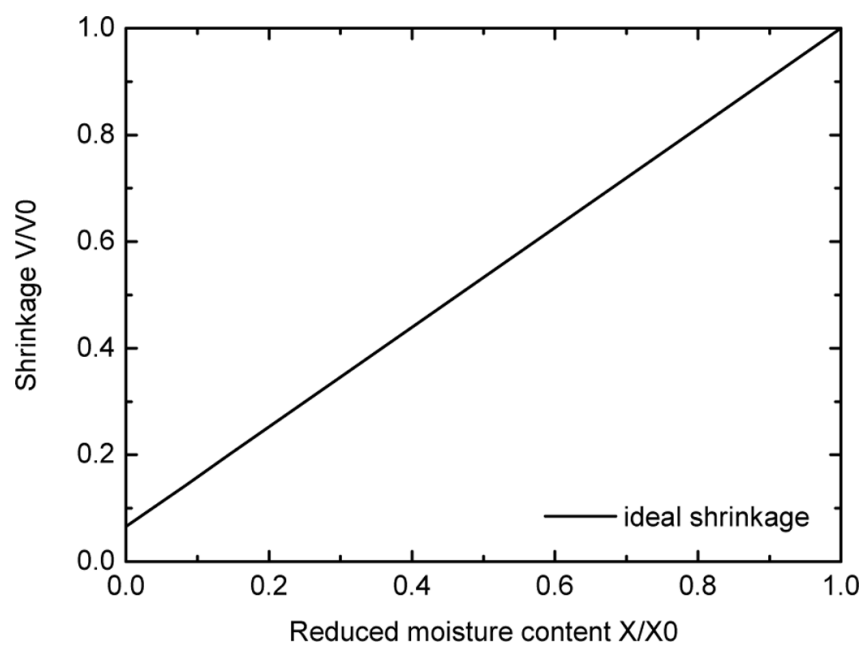

FIG. 1. Ideal shrinkage curve with or without initial porosity. dicts some attempts reported in the literature to fit the ideal shrinkage models by introducing an initial porosity. ${ }^{[14]}$

The initial porosity is not straightforward to determine, so it is preferable to measure the apparent initial density $\rho_{0}$ and the true solid density $\rho_{S}$ and calculate the porosity using the following equation:

$$
\varepsilon_{0}=1-\frac{\rho_{0}}{\rho_{S}} \frac{1+\beta X_{0}}{1+X_{0}}
$$

\section{Case (c) Non-Ideal Shrinkage without Initial \\ Porosity; $\boldsymbol{\varepsilon} \neq \mathbf{0}, \quad \varepsilon_{0}=\mathbf{0}$}

For non-ideal shrinkage with no initial porosity, Eq. (6) reduces to

$$
(1-\varepsilon) z=A(\beta) \frac{X}{X_{0}}+B(\beta)
$$

where $z$ represents the experimental shrinkage curve for a product with non-ideal shrinkage.

The porosity change can easily be deduced from Eqs. (9) and (11).

$$
\varepsilon=\frac{z-y}{z}
$$

The previous equation has a graphical interpretation on the shrinkage diagram (Fig. 2). The porosity is seen as the ratio $\varepsilon=A B / A C$. For most products, porosity increases as the experimental shrinkage curve departs from the ideal one.

\section{General Case: Non-Ideal Shrinkage with Initial \\ Porosity; $\boldsymbol{\varepsilon} \neq \mathbf{0}, \quad \varepsilon_{0} \neq \mathbf{0}$}

In the general case, the shrinkage behavior is given by Eq. (6). It can be easily shown that the porosity is deduced

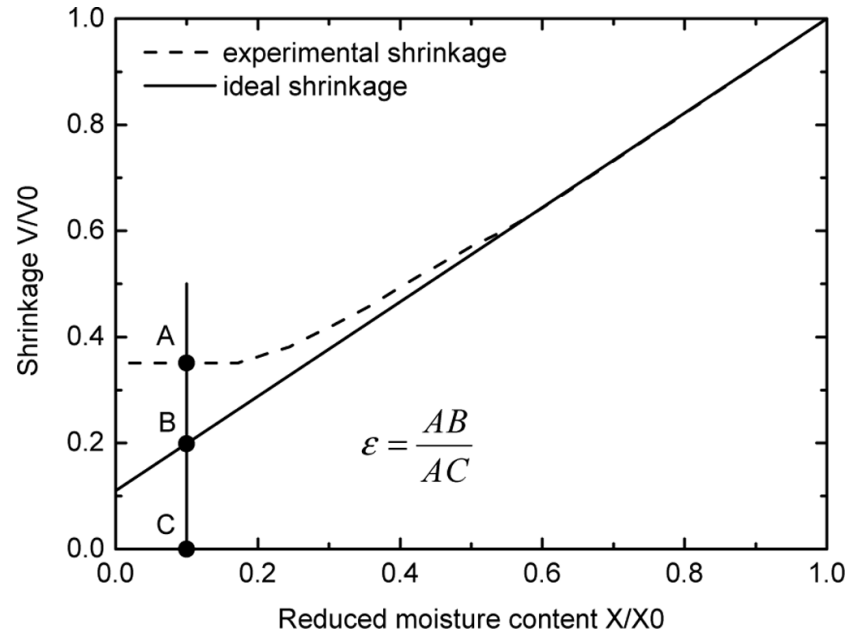

FIG. 2. Non-ideal shrinkage curve without initial porosity: ideal shrinkage curve (plain line); experimental curve (dashes). 


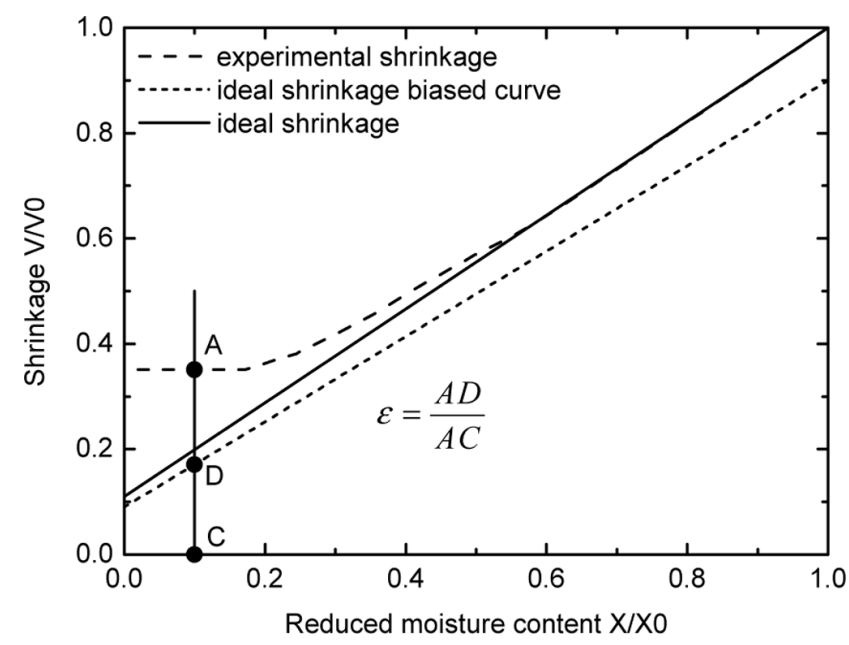

FIG. 3. Non-ideal shrinkage curve with initial porosity $\varepsilon_{0}$ : ideal shrinkage curve (plain line); ideal shrinkage biased curve taking initial porosity into account (small dots); experimental curve (dashes).

from $z$ and $y$ through the equation:

$$
\varepsilon=\frac{z-\left(1-\varepsilon_{0}\right) y}{z}
$$

Equation (12) also has a graphical interpretation on the shrinkage diagram (Fig. 3). A new baseline (ideal shrinkage "biased" curve) is deduced from the ideal shrinkage curve by multiplying it by the quantity $\left(1-\varepsilon_{0}\right)$. The porosity is deduced in a similar way as for case (b), using this new baseline $\varepsilon=A D / A C$.

\section{APPLICATIONS OF THE METHOD IN VARIOUS DOMAINS}

The proposed method was tested on a variety of products (food, gels, sludge) with different drying techniques. Experimental results were taken from the abundant literature in the field.

\section{Convective Drying of Carrot: Case (a)}

The shrinkage of carrot is reported to be ideal for convective drying. However, numerous methods were proposed to fit experimental data, some of them including initial porosity. ${ }^{[8,11,14]}$ Zogzas and co-authors ${ }^{[10]}$ tested convective drying of three food products (namely apple, potato, and carrot) with a fixed air temperature $\left(70^{\circ} \mathrm{C}\right)$ and velocity $(2.5 \mathrm{~m} / \mathrm{s})$ and different relative humidity $(20$, 30,45 , and $60 \%$ ). The experimental devices used were the electronic scale Mettler AE-160 with an accuracy of $10^{-4} \mathrm{~g}$ for the determination of the mass change during drying and the stereopycnometer Beckmann 930 with an accuracy of $0.01 \mathrm{~mL}$ for the measurement of the void fractions in the samples. N-heptane was used to measure the apparent specific mass by immersing the sample and measuring the volume change with an accuracy of $0.05 \mathrm{~mL}$. With the three measurements on the sample, it was possible to determine the solid density, the apparent density, the porosity, and the specific volume as a function of the moisture content $X$.

Using the experimental values of $\rho_{S}, \rho_{0}, \rho_{L}$ given by the authors (Table 2), the present model was tested. Assuming an ideal shrinkage $(\varepsilon=0)$, Eq. (9) applies and shows a good agreement with the experimental data (Fig. 4), which means that the porosity can be neglected. Assuming deviations of experimental points $(z)$ from ideal behavior $(y)$, and using Eq. (12), very small porosity (order of magnitude $2 \%$ ) can be detected, very much comparable to experimental results obtained by Zogzas and co-authors. ${ }^{[10]}$ Only few negative values of porosity exist in spite of the experimental errors (Fig. 5).

\section{Freeze Drying of Banana Slices: Case (b)}

Krokida and Maroulis ${ }^{[12]}$ have studied different drying techniques for four food products, namely apple, potato, banana, and carrot. Except for the stereopycnometer, which was changed for a more precise instrument (Quantachrome stereopycnometer with an accuracy of $0.001 \mathrm{~mL}$ ), the experimental techniques were identical to the ones used by Zogzas et al. ${ }^{[10]}$ Among the five drying techniques, freeze drying offers minimal shrinkage. The samples were frozen at $-35^{\circ} \mathrm{C}$ for $48 \mathrm{~h}$, maintained in liquid nitrogen for one hour, and then freeze-dried using a Lyovac GT2 laboratory freeze-dryer. Small volume change (Fig. 6) is accompanied by large porosities as shown in Fig. 7. The initial porosity was very small $(0.28 \%)$. Using the calculation method described in the previous section, it is quite remarkable that

TABLE 2

Values of the parameters used in the present study

\begin{tabular}{lcccccc}
\hline Material & $\begin{array}{c}\text { Initial } \\
\text { apparent density } \\
\left(\mathrm{kg} / \mathrm{m}^{3}\right)\end{array}$ & $\begin{array}{c}\text { Solid true } \\
\text { density } \\
\left(\mathrm{kg} / \mathrm{m}^{3}\right)\end{array}$ & $\begin{array}{c}\text { Liquid } \\
\text { true density } \\
\left(\mathrm{kg} / \mathrm{m}^{3}\right)\end{array}$ & $\begin{array}{c}\text { Initial } \\
\text { moisture content } \\
(\mathrm{kg} / \mathrm{kg})\end{array}$ & $\begin{array}{c}\text { Calculated } \\
\text { initial porosity } \\
(\%)\end{array}$ & References \\
\hline Carrot & 1056 & 1610 & 1020 & 9.82 & 0 & Zogzas et al. $^{[10]}$ \\
Banana & 1053.9 & 1920 & 1000 & 4.93 & 3.12 & Krokida and Maroulis $^{[12]}$ \\
Sludge & 937 & 1700 & 1000 & 5.6 & 12.15 & Léonard et al. $^{[4]}$ \\
Xerogel & 879 & 2000 & 800 & 5.7 & 0 & Bisson et al. \\
\hline
\end{tabular}




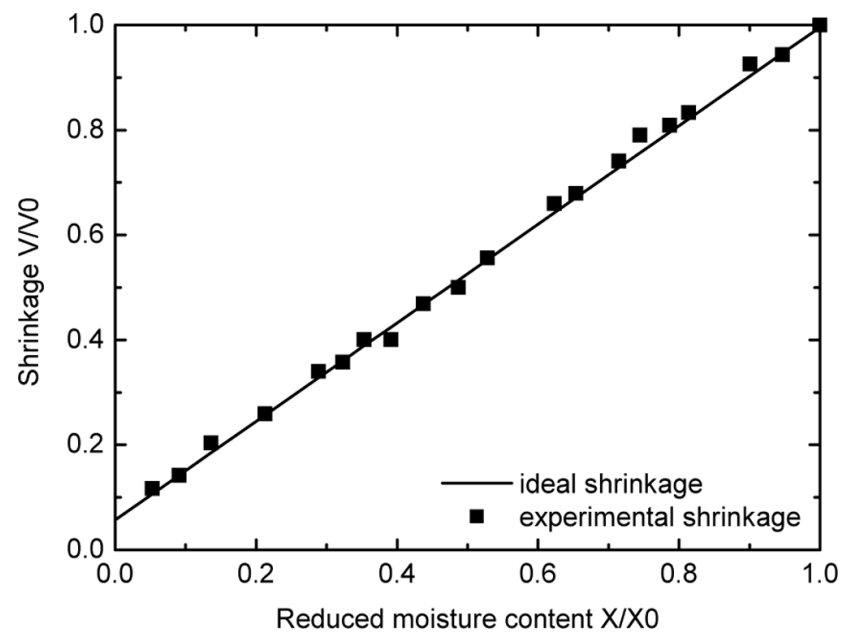

FIG. 4. Convective drying of carrot: comparison of ideal shrinkage curve (plain line) using Eq. (9) and experimental shrinkage curve ( Zogzas et al. ${ }^{[10]}$ ).

the calculated porosity was very close to the experimental porosity. The porosity varies almost linearly with the mass, which is an indication that a homogeneous dried porous structure is formed.

\section{Sludge Convective Drying: General Case}

Sludge convective drying was studied by Leonard and coworkers. ${ }^{[4]}$ The shrinkage curves shown in Fig. 8 were obtained for a sludge from a municipal wastewater treatment plant (City of Retinne, Belgium). The drying kinetics were obtained using a drying tunnel with different absolute humidity $(0.006,0.15$, and $0.41 \mathrm{~kg} / \mathrm{kg}$ dry air), temperatures $\left(80,120\right.$, and $\left.160^{\circ} \mathrm{C}\right)$, and air velocities $(1,2$, and $3 \mathrm{~m} / \mathrm{s})$. Extruded cylindrical samples were periodically removed

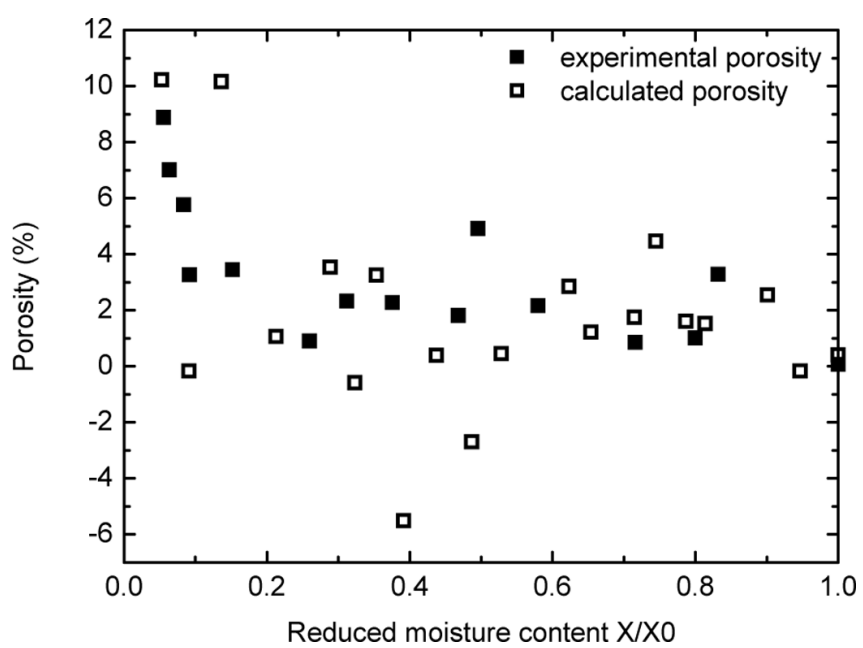

FIG. 5. Convective drying of carrots: comparison of experimental porosity measurements ( $\mathbf{\square}$ : Zogzas et al. ${ }^{[10]}$ ) and calculations derived from Eq. (13) ( $\square)$.

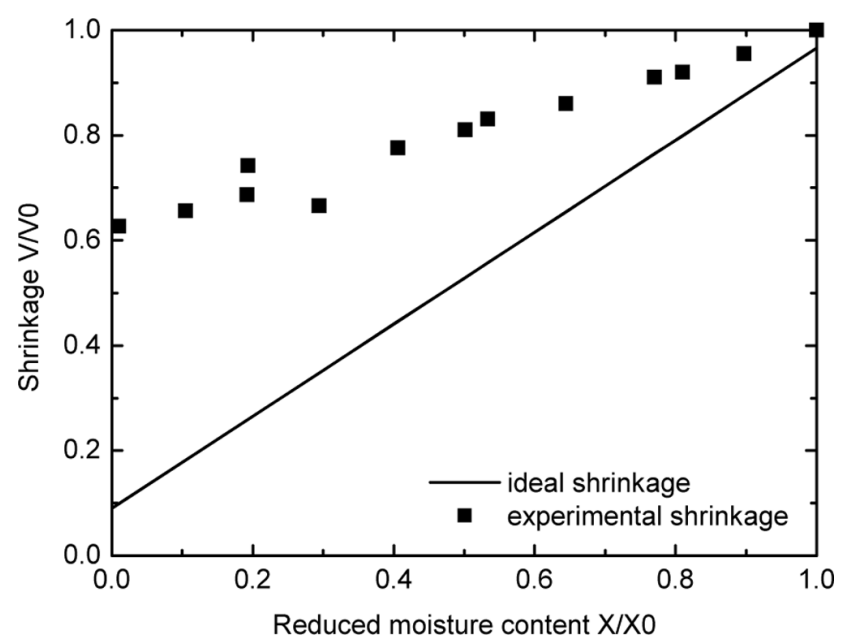

FIG. 6. Freeze drying of banana slices: ideal shrinkage curve (plain line) and experimental shrinkage curve ( $\square$ : Krokida and Maroulis $\left.{ }^{[12]}\right)$.

from the drying tunnel and scanned using an X-ray microtomography (Skyscan, Belgium) to determine the surface change, shrinkage, and cracks formation during the drying process. An average diameter was derived using image analysis, from which the volume and the external surface were calculated. The mass of the sample was determined every $5 \mathrm{~s}$.

Equation (10) used with the parameters given by the authors (Table 2) showed that initial porosity was not negligible (this porosity may be explained by the formation of micro-bubbles during sludge extrusion into cylindrical samples).

The experimental curve for a typical drying experiment $\left(80^{\circ} \mathrm{C}, 1 \mathrm{~m} / \mathrm{s}\right)$ is plotted in Fig. 8 . The corresponding ideal

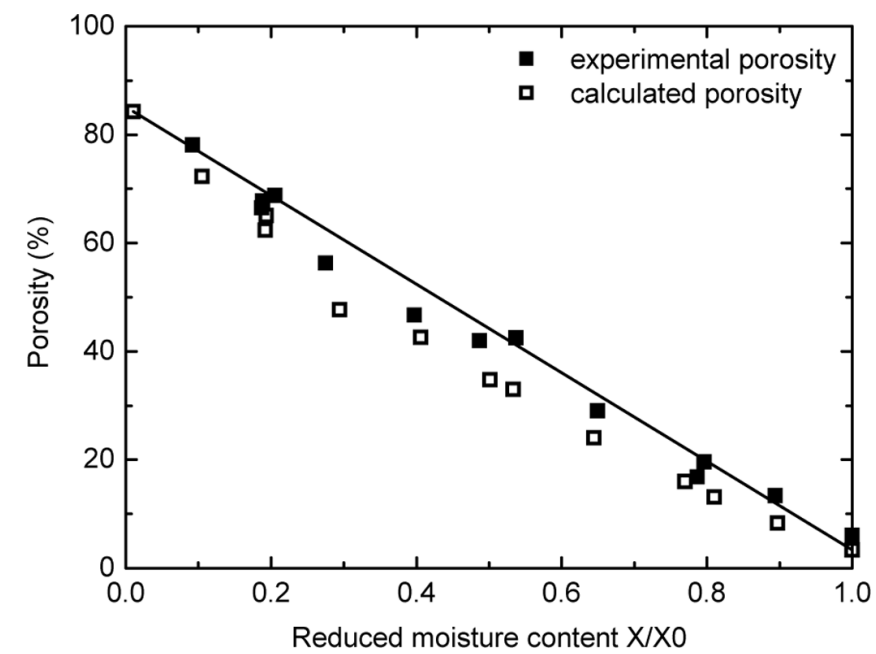

FIG. 7. Freeze drying of banana slices: comparison of experimental porosity measurements ( $\square$ : Krokida and Maroulis ${ }^{[12]}$ ) and calculations derived from Eq. (13). 


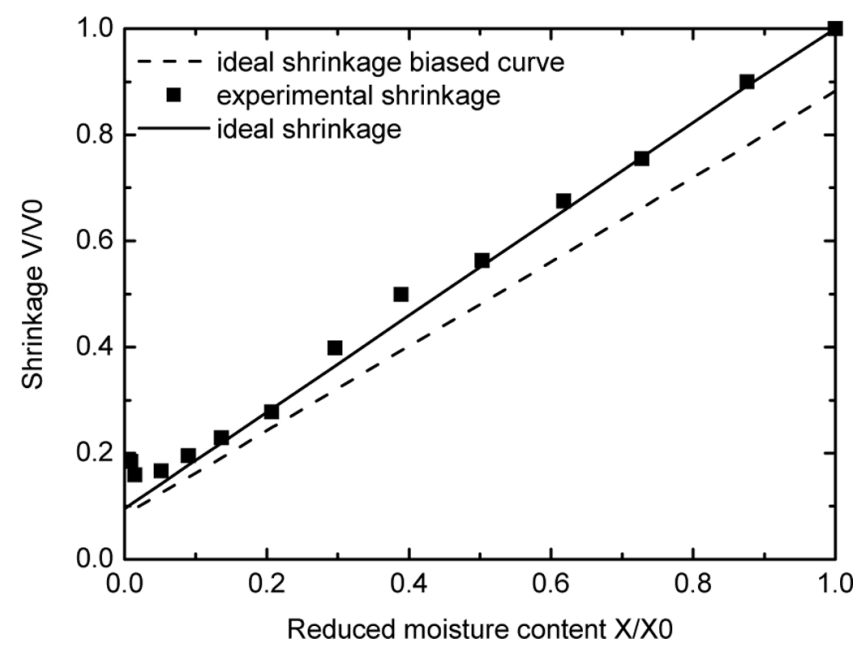

FIG. 8. Convective drying of Retinne sludge: ideal shrinkage "biased curve" (-) and experimental shrinkage curve ( $\square$ : Léonard $\left.{ }^{[15]}\right)$.

shrinkage "derived curve" with internal porosity is also plotted (as described in the previous section and Fig. 3). The porosity change is calculated using Eq. (13), showing that the initial porosity was around $12 \%$ for an important part of the drying process, then slightly decreasing before increasing again when the sample was almost dry (Fig. 9). Although no porosity measurements were made for this experiment, X-ray tomography allowed calculating the volume of cracks during the drying process. Cracks are large cavities in the sludge: only cracks some orders of magnitude larger than the microtomograph resolution $(41 \mu \mathrm{m})$ can be seen. The porosity obtained from the addition of the initial porosity and the porosity (Fig. 10) derived from the measurement of cracks volume is in good agreement with the porosity calculated using Eq. (13).

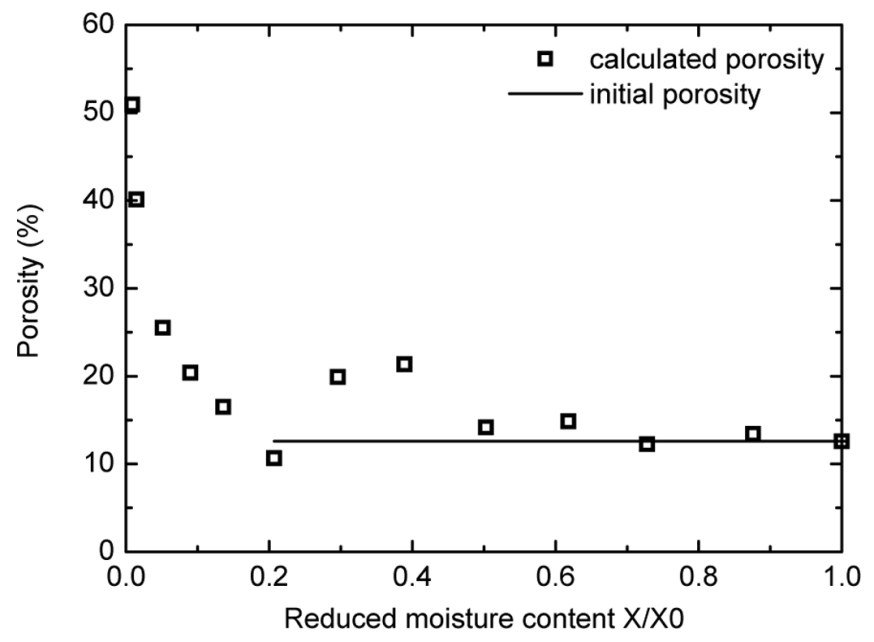

FIG. 9. Convective drying of Retinne sludge: porosity development calculations from Eq. (13).

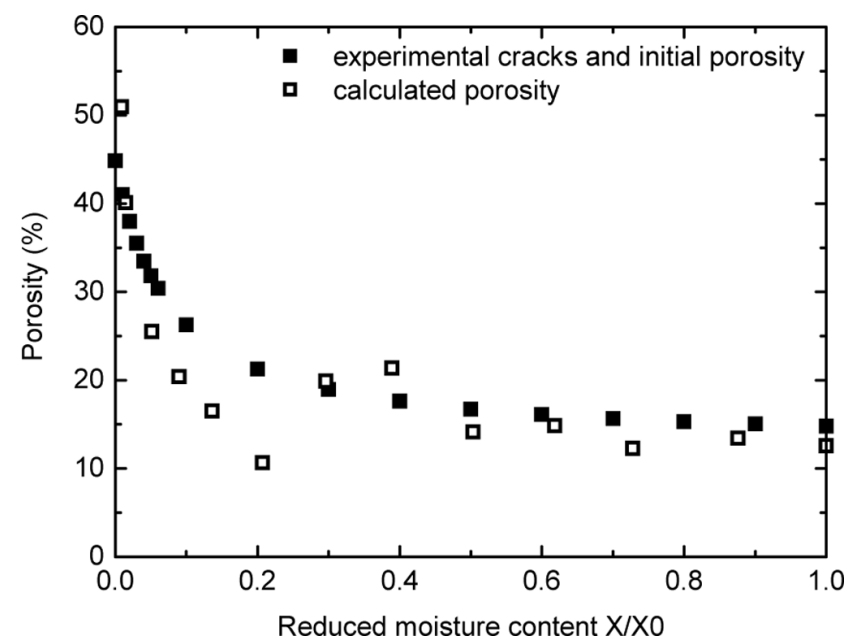

FIG. 10. Convective drying of Retinne sludge: comparison of calculated porosity using Eq. (13) ( $\square$ ) and the porosity obtained by adding the initial porosity and the porosity calculated from image analysis of cracks ( Léonard $\left.^{[15]}\right)$.

This validates the fact that crack formation is mainly responsible for porosity development in the convective drying of this particular sludge.

\section{Silica Xerogels: General Case}

Convective drying of silica gels is a delicate operation because of the importance of shrinkage and risks of cracks due to high strains in the material. Bisson and co-authors ${ }^{[3]}$ have improved the hydrophobic properties of silica gels by a surface treatment allowing the dried gel (xerogels) to resume the size and shape of the original wet silica gel, thus conferring to the dried gel excellent insulating properties. ${ }^{[36]}$ Isopropanol was used as solvent. Gel spherical

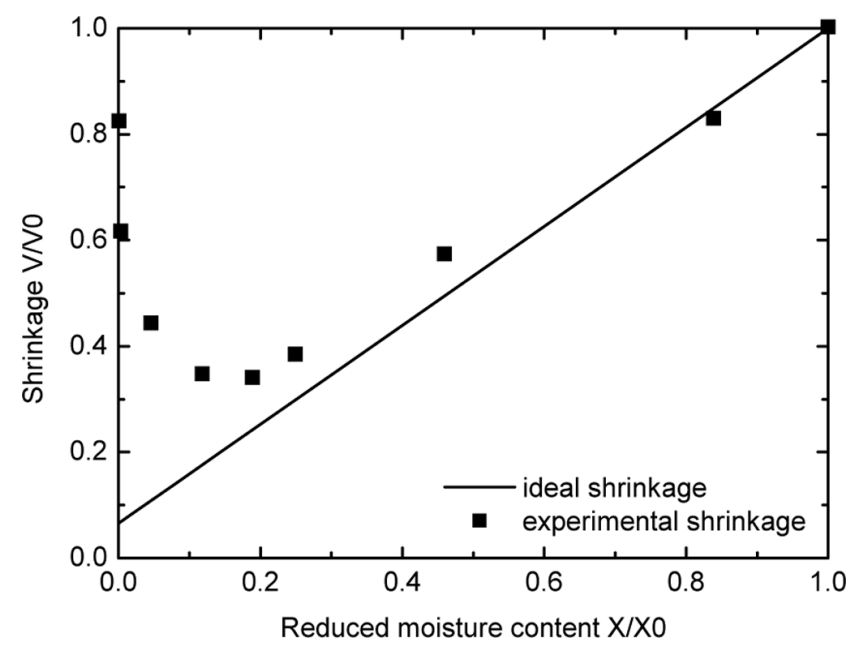

FIG. 11. Convective drying of xerogels: ideal shrinkage curve (plain line) and experimental shrinkage curve ( $\square$ : Bisson $\left.{ }^{[3]}\right)$. 


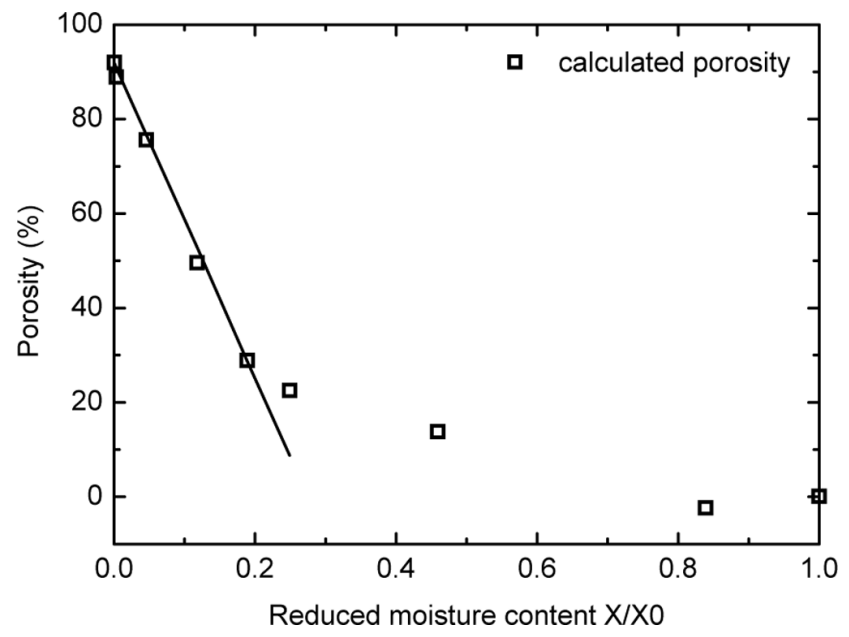

FIG. 12. Porosity development in a xerogel vs. isopropanol content during drying $\left(\square\right.$ : Bisson $\left.{ }^{[3]}\right)$.

granules were dried under a flow of nitrogen $(0.05 \mathrm{~L} / \mathrm{min})$ in a DVS apparatus (Dynamic Vapor Sorption; Surface Measurements Systems Inc., London, UK). The sizes of the gel granules were estimated by photography and image processing. One typical shrinkage curve of a dried xerogel is shown in Fig. 11. Using the experimental values of $\rho_{S}$, $\rho_{0}$, and $\rho_{L}$, (Table 2), the ideal shrinkage curve (Eq. (9)) was plotted and compared with experimental values. It was shown that a first period of intense ideal shrinkage was followed by a period of expansion of the outer skin of dried xerogel. ${ }^{[36]}$ The cracks appeared during this expansion phase. This very unusual shrinkage curve indicates a strong porosity increase in the xerogel as indicated in Fig. 12. For the surface-treated xerogel, the porosity can be better than 0.90 , which shows the quality of the drying process for the making of dried insulated particles. As for the case of freeze drying of banana slices, it can be seen that the porosity varies almost linearly with the mass in the second period (expansion), which is an indication that a homogeneous dried porous structure is formed (Fig. 12).

\section{CONCLUDING REMARKS}

The Katekawa-Silva ${ }^{[1]}$ model allows relating shrinkage and porosity with three lumped parameters: the initial density of the moist product, the true density of the solid phase, and the true density of the liquid phase. These parameters can be obtained from direct measurements or data collections. The assumptions of the model are wide enough to apply this method to a large range of materials and solvents. In the present article, a graphical derivation of the porosity change during the shrinkage process is proposed. The graphical approach allows checking immediately some assumptions and the quality of the measurements. For three of the studied materials (carrot, xerogels, banana), the initial porosity was negligible. For sludge, the initial porosity was important. The use of Eqs. (10) and (13) is thus very helpful for a correct interpretation of the shrinkage curves.

The comparison of the porosity calculated by the present method and experimental determinations may validate that the experimental methods have taken into account the whole spectrum of porosities (micropores or mesopores, for instance). As a mass balance method, this calculation method is only sensitive to accuracy of the volume and mass measurements. Though very good precision on the mass measurements can be obtained, volume measurement is more difficult to perform, especially when the material is anisotropic. A development of the present method, currently under study, is to determine the volume change by $3 \mathrm{D}$ stereovision and image analysis. The instantaneous and precise determination of volume and mass change may be then used as a powerful tool for the online control of porosity development in a product during a drying process.

\section{NOMENCLATURE}

$\begin{array}{ll}\mathrm{m} & \text { Mass }(\mathrm{kg}) \\ \mathrm{V} & \text { Volume }\left(\mathrm{m}^{3}\right) \\ \mathrm{X} & \text { Moisture content }(\mathrm{kg} \text { of water } / \mathrm{kg} \text { of dry } \\ & \text { solid) }\end{array}$

\section{Greek Letters}

$\begin{array}{ll}\varepsilon & \text { Porosity } \\ \rho & \text { Apparent den } \\ \rho_{\mathrm{L}} & \text { Density of liqu } \\ \rho_{\mathrm{S}} & \text { Density of so } \\ \text { Subscripts } & \\ e & \text { equilibrium } \\ 0 & \text { initial } \\ S & \text { solid } \\ L & \text { liquid }\end{array}$

\section{REFERENCES}

1. Katekawa, M.E.; Silva, M.A. Study of porosity behavior in convective drying of bananas. In Proceedings of the 14th International Drying Symposium (IDS 2004), Sao-Paulo, Brazil, August 22-25, 2004; B, 1427-1434.

2. Nadeau, J.P.; Puiggali, J.R. Séchage des processus physiques aux procédés industriel, 1st ed.; Technique et Documentation Lavoisier: Paris Cedex, 1995.

3. Bisson, A.; Rodier, E.; Rigacci, A.; Lecomte, D.; Achard, P. Study of evaporative drying of treated silica gels. Journal of Non-Crystalline Solids 2004, 350, 230-237.

4. Leonard, A.; Blancher, S.; Pirard, R.; Marchot, P.; Pirard, J.P.; Crine, M. Multiscale texture characterization of wastewater sludges dried in a convective rig. Drying Technology 2003, 21 (8), 1507-1526.

5. Bigot, A. Retrait au Séchage des Kaolins et Argiles; Compte Rendu de l'Académie des Sciences, Paris, 1921.

6. Stenström, S. Product engineering by the paper dryer. In Proceedings of the 14th International Drying Symposium (IDS 2004), Sao-Paulo, Brazil, August 22-25, 2004; A, 89-98. 
7. Lozano, J.E.; Rotstein, E.; Urbicain, M.J. Total porosity and openpore porosity in the drying of fruits. Journal of Food Science 1980, 45, 1403-1407.

8. Lozano, J.E.; Rotstein, E.; Urbicain, M.J. Shrinkage, porosity and bulk density of foodstuffs at changing moisture contents. Journal of Food Science 1983, 48, 1497-1502.

9. Ratti, C. Shrinkage during drying of foodstuffs. Journal of Food Engineering 1994, 23(1), 91-105.

10. Zogzas, N.P.; Maroulis, Z.B.; Marinos-Kouris, D. Densities, shrinkage and porosity of some vegetables during air drying. Drying technology 1994, 12 (7), 1653-1666.

11. Rahman, M.S.; Perera, C.O.; Chen, X.D.; Driscoll, R.H.; Potluri, P.L. Density, Shrinkage and porosity of calamari mantle meat during air drying in a cabinet dryer as a function of water content. Journal of Food Engineering 1996, 30, 135-145.

12. Krokida, M.K.; Maroulis, Z.B. Effect of drying method on shrinkage and porosity. Drying Technology 1997, 15 (10), 2441-2458.

13. May, B.K.; Perré, P. The importance of considering exchange surface area reduction to exhibit a constant drying flux period in foodstuffs. Journal of Food Engineering 2002, 54, 271-282.

14. Mayor, L.; Sereno, A.M. Modelling shrinkage during convective drying of food material: A review. Journal of Food Engineering 2004, 61, 373-386.

15. Léonard, A. Etude du séchage convectif des boues de station d'épuration suivi de la texture par microtomographie à rayons $X$; Thèse de doctorat, Université de liège, 2003.

16. Kribi, S.; Joyau, A.; Nzihou, A.; Arlabosse, P. Influence of the phosphoric acid addition on the drying kinetics of dredged sediment. In Proceedings of the 14th International Drying Symposium (IDS 2004), Sao-Paulo, Brazil, August 22-25, 2004; B, 1013-1020.

17. Bonazzi, C.; Ripoche, A.; Michon, C. Moisture diffusion in gelatin slabs by modeling drying kinetics. Drying Technology 1997, 15 (6/8), 2045-2059.

18. McMinn, W.A.M.; Magee, T.R.A. Physical characteristics of dehydrated potatoes-Part I. Journal of Food Engineering 1997, 33, $37-48$.

19. Azzouz, S.; Jomaa, W.; Belghith, A. Drying kinetic equation of single layer of grapes. In IDS'98, Proceedings 11th International Drying Symposium (IDS '98), Halkidiki, Greece, August 19-22, 1998; B, 988-997.

20. Vaxelaire, J.; Puiggali, J.R. Analysis of the drying of residual sludge: From the experiment to the simulation of a belt dryer. Drying Technology 2002, 20 (4\&5), 989-1008.
21. Rahman, M.S. Handbook of Food Properties, CRC Press: Boca Raton, FL, 1995.

22. Smith, D.M.; Scherer, G.W.; Anderson, J.M. Shrinkage during drying of silica gel. Journal of Non-Crystalline Solids 1995, 188, 191-206.

23. Kilpatrick, P.W.; Lowe, E.; Van Ardsel, W.B. Tunnel dehydrators for fruit and vegetables. In Advances in Food Research 6; Mrak, E.M.; Stewart, G.F., Eds.; Academic Press: New York, 1955; 313-372.

24. Suzuki, K.; Kubota, K.; Hasegawa, T.; Hosaka, H. Shrinkage in dehydratation of root vegetables. Journal of Food Science 1976, 41, 1189-1193.

25. Wang, N.; Brennan, J.G. Changes in structure, density and porosity of potato during dehydratation. Journal of Food Engineering 1995, 24, 61-76.

26. Azzouz, S.; Guizani, A.; Jomaa, W; Belgith, A. Moisture diffusivity and drying kinetic equation of convective drying of grapes. Journal of Food Engineering 2002, 55 (4), 323-330.

27. Talla, A.; Puiggali, J.R.; Jomaa, W.; Jannot, Y. Shrinkage and density evolution during drying of tropical fruits: Application to banana. Journal of Food Engineering 2004, 64, 103-109.

28. Rahman, M.S., Potluri, P.L. Shrinkage and density of squid flesh during air drying. Journal of Food Engineering 1990, 12, 133-143.

29. Perez, M.G.; Calvelo, A. Modeling the thermal conductivity of cooked meat. Journal of Food Science 1984, 49, 152-156.

30. Levi, G.; Karel, M. Volumetric shrinkage (collapse) in freeze-dried carbohydrates above their glass transition temperature. Food Research International 1995, 28 (2), 145-151.

31. Tari, G.; Ferreira, J.M.F.; Fonseca, A.T. Influence of particle size and particle size distribution on drying-shrinkage behaviour of alumina slip cast bodies. Ceramics International 1999, 25, 577-580.

32. Siau, J.F. Transport Processes in Wood. Springer-Verlag: Berlin, 1984

33. Schoch, K.F.; Panackal, P.A.; Franck, P.P. Real time measurement of resin shrinkage during cure. Thermochimica Acta 2004, 417, 115-118.

34. Slowik, V.; Schlattner, E.; Klink, T. Experimental investigation into early age shrinkage of cement paste by using fibre Bragg gratings. Cement \& Concrete Composites 2004, 26, 473-479.

35. Vacarezza, L. Cinetica y mecanismo de transporte de agua durante la deshidrataci_on de la remolacha azucarera; Ph.D. Thesis, Universidad de Buenos Aires, 1975.

36. Bisson, A.; Rigacci, A.; Lecomte, D.; Achard, P. Effective thermal conductivity of divided silica xerogel beds. Journal of Non-Crystalline Solids 2004, 350, 379-384. 